\title{
The Emergence of Transition Metal-Mediated Hydrothiolation of Unsaturated Carbon-Carbon Bonds: A Mechanistic Outlook
}

\author{
Ricardo Castarlenas, * Andrea Di Giuseppe, Jesús J. Pérez-Torrente, Luis A. Oro*
}

The hydrothiolation of unsaturated carbon-carbon bonds is a practical and atom-economical approach for the incorporation of sulfur into organic frameworks. In recent years, we have witnessed the development of a range of transition metal-based catalytic systems for the control of the regio- and stereoselectivity. This minireview aims to highlight the mechanistic background behind this transformation in order to help for the design of more specific and active organometallic hydrothiolation catalysts.

\section{Introduction}

The development of efficient synthetic methods for the incorporation of sulfur into organic frameworks is nowadays an important task due to the practical applications of this type of compounds as pharmaceuticals, functional materials, or synthetic reagents. ${ }^{[1-4]}$ In this context, one of the simplest and atomeconomical approach is the direct addition of sulfur and hydrogen atoms from thiols to unsaturated carbon-carbon bonds, commonly known as hydrothiolation or, alternatively, thiol-ene(yne) coupling. ${ }^{[5]}$ This transformation, which has been known since the beginning of the last century, ${ }^{[6]}$ can be promoted by free radicals, ${ }^{[7]}$ strong acids ${ }^{[8]}$ or bases, ${ }^{[9]}$ although it generally occurs with poor selectivity control and the formation of unwanted by-products. Alternatively, metal catalysts offer the potential for mild reaction conditions with a high degree of regio- and stereo-selectivity, but it is only recently that these processes have impressively emerged. This breakthrough might be due to the overcome of the established belief that sulfur compounds are potent poisons for metal catalysts. ${ }^{[10]}$ Indeed, several metal species based on $\mathrm{Mo},{ }^{[11,26]} \mathrm{Ti},{ }^{[12]}$ $\mathrm{Al},{ }^{[12 \mathrm{~b}, 13]} \mathrm{Pd}{ }^{[14,16 \mathrm{~b}]} \mathrm{Pt},{ }^{[14 \mathrm{c}, 15,16 \mathrm{~b}]} \mathrm{Ni}{ }^{[16]} \mathrm{Ru},{ }^{[16 b, 17]} \mathrm{Fe},{ }^{[18]} \mathrm{Rh}^{[14 \mathrm{c}, 19,20]}$ $\mathrm{Ir}^{[11,20]} \mathrm{Cu},{ }^{[21]} \mathrm{Au},{ }^{[22]} \mathrm{Co},{ }^{[23]} \mathrm{In},{ }^{[13,24]} \mathrm{Mn},{ }^{[25]} \mathrm{W},{ }^{[26]} \mathrm{Cr},{ }^{[26]} \mathrm{Zr},{ }^{[27]} \mathrm{An}$ $(\mathrm{Th}, \mathrm{U})^{[28]}$, or $\mathrm{Ln}(\mathrm{La}, \mathrm{Sm}, \mathrm{Lu}, \mathrm{Nd}, \mathrm{Y})^{[28 \mathrm{~b}]}$ have been revealed as effective promoters for this transformation, although control of the stereo- and regioselectivity still remains an important challenge. A feasible way to approach this goal is to design more specific and active organometallic catalysts, for which is certainly essential an in-depth understanding of the mechanistic issues, and indeed, it could be useful to other diverse hydroelementation transformations such as hydroalkoxylation, hydrophosphination, hydroamination, or hydroacylation, among others. Our aim in this concise survey is to analyze the different mechanistic pathways rather than to present a comprehensive overview of a research area that has already been covered in several recent reviews. ${ }^{[1,5]}$ The sulfa-michael additions mediated by organocatalysts remains beyond the scope of this minireview. ${ }^{[29]}$

\section{General Mechanistic Aspects}

The hydrothiolation of carbon-carbon multiple bonds is a multifaceted reaction as far as its mechanistic pathway is concerned (Figure 1). This reaction can proceed via free radicals, ${ }^{[3 \mathrm{c}, 5 \mathrm{e}, 7]}$ or ionic processes (acid ${ }^{[8]}$ or base-initiated ${ }^{[9]}$ ), or can be metal-catalyzed. ${ }^{[11-}$ ${ }^{28]}$ However, irrespective of the promoter, two general approaches can be envisaged, namely, activation of the thiol or alternatively that of the unsaturated bond. In first case the reaction can be triggered either by: $i$ ) formation of free radicals, ii) increase of the nucleophilicity of the sulfur atom by a base or a metal, or iii) oxidative addition of the $\mathrm{S}-\mathrm{H}$ bond to an organometallic catalyst. Furthermore, activation of the unsaturated bond can be classified into: i) Brönsted or Lewis acids or ii) interaction with organometallic species via $\eta^{2}$-coordination or vinylidene intermediates.

[*] Dr. R. Castarlenas, Dr. A. Di Giuseppe, Prof. J. J. PérezTorrente, Prof. L. A. Oro Instituto Síntesis Química y Catálisis Homogénea Departamento de Química Inórganica, CSIC - Universidad de Zaragoza. Facultad de Ciencias, PI. S. Francisco S/N 50009 Zaragoza, Spain E-mail: oro@unizar.es, rcastar@unizar.es

[**] Financial support from the MICINN of Spain Project CTQ2010-15221), the Diputación General de Aragón (E07), the ARAID Foundation under the program "Jóvenes Investigadores", and CONSOLIDER INGENIO-2010, under the Project MULTICAT (CSD2009-00050) are gratefully acknowledged. 


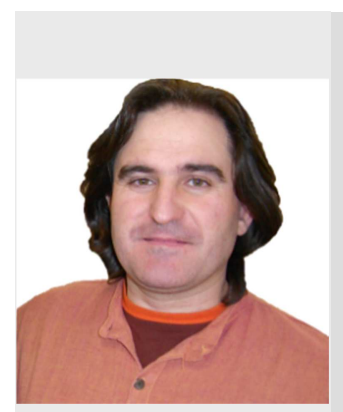

Ricardo Castarlenas was born in Estadilla (Spain) in 1973. He studied at the University of Zaragoza where he obtained his doctorate with Prof. Esteruelas in 2001. After a postdoctoral stay at the University of Rennes under the supervision of Prof. Dixneuf, he returned to the University of ZaragozaCSIC in 2004 where he gained a Ramon y Cajal contract in 2006 . In 2008 he was awarded the Spanish Royal Society of Chemistry prize for young researchers. Since 2009 he has been project leader for the design of organometallic catalysts for organic transformations in a selective manner.

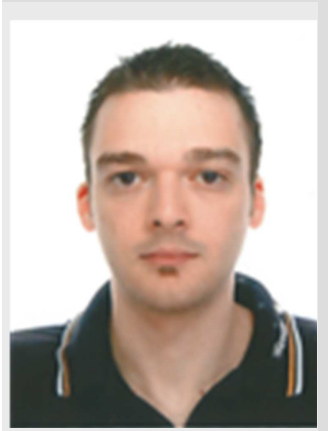

Andrea Di Giuseppe was born in L'Aquila in 1981 and studied chemistry at the University of L'Aquila. He gained his $P h D$ degree in 2012 under the supervision of Prof. F. De Angelis. His research interest concerns the development of new transition metalbased catalytic systems for fine chemical production in homogeneous and heterogeneous phase.

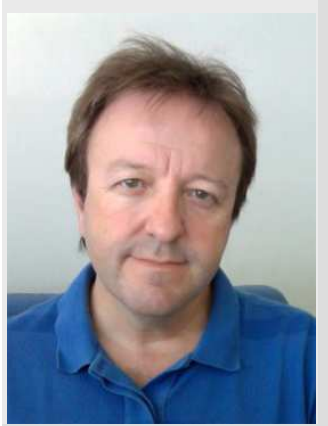

Jesús J. Pérez-Torrente was born in Barbastro (Spain) in 1962. He obtained his Ph.D. in 1989 from the University of Zaragoza. He was a post-doctoral fellow at Oxford University (1990-91) under the supervision of Prof. Dr. J. M. Brown, Lecturer in Inorganic Chemistry in 1995, and full Professor in 2010 at the University of Zaragoza. He has been a member of the Management Team of the Homogeneous Catalysis Institute since 2004. His research interest focuses on the design of coordination and organometallic entities for homogeneous and heterogeneous catalytic applications.

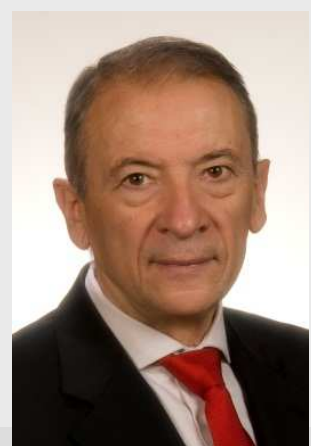

Luis A. Oro has been professor of Chemistry at the University of Zaragoza since 1982, and head of the Homogeneous Catalysis Institute since 2004. His main research interests are in organometallic chemistry and homogeneous catalysis with a special interest in reaction mechanisms, and he has coauthored well over 500 scientific papers. He is co-author or coeditor of seven books. He has received numerous national and international awards and honors, and is member of several international scientific academies.

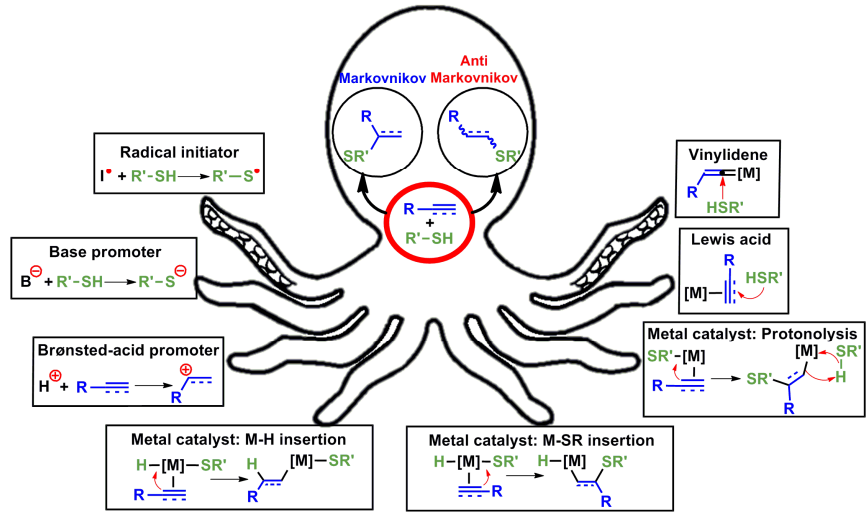

Figure1. The multifaceted mechanistic nature of hydrothiolation.

The characteristics of the thiol and the unsaturated substrate strongly determine their efficiency within the different catalytic pathways (Figure 2). Aromatic thiols are better radical chain transfer agents than to aliphatic thiols, thus reducing telomerization of the unsaturated reagent. Besides this, the higher acidity of aromatic thiols favors both their oxidative addition to unsaturated organometallic complexes and protonolysis, whereas the enhanced nucleophilicity of aliphatic thiolate ligands increases the rate of migratory insertion. As a result, the rate-determining step for the catalytic cycle may differ depending on the nature of the thiol. As far as the unsaturated substrate is concerned, it is well known that radicals react faster with alkenes than with alkynes, thus meaning that dithioacetals, which result from double addition of the thiol, are observed in radical-initiated alkyne hydrothiolation. ${ }^{[7 a]}$ In contrast, alkynes interact strongly with transition metal-species via $\pi$ coordination or by migratory insertion into $\mathrm{M}-\mathrm{X}$ bonds. Allenes also react with thiols via $\pi$-coordination to the metal center.

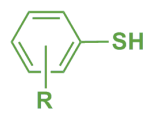

- Radical Stabilized

- More Acid: Favors Oxidative Addition

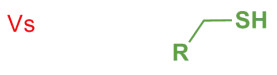
Enhance Migratory-Insertion
- Thiolate More Nucleophilic:

$$
\begin{array}{cc}
\mathbf{R}=\text { Radical Favored } \\
\text { Acid, [Pd], [Ni], [Ln], [Rh] } \alpha \text {-isomer, Markovnikov } \\
\text { R-isomers, anti-Markovnikov }
\end{array}
$$

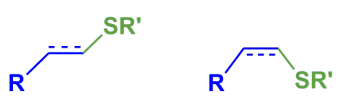

Figure 2. Influence of the unsaturated substrate and thiol on hydrothiolation reactions.

Table 1 shows some reported activity and selectivity data for the standard addition of thiophenol to phenylacetylene. This coupling takes place smoothly at room temperature after $30 \mathrm{~h}$ in $90 \%$ yield in the absence of catalyst, probably via radical species, with high regioselectivity for $\beta$-isomers (entry 1). Other base- or radicalmediated reactions display similar selectivity. More noticeable is the complete selectivity for the Markovnikov-vinyl sulfide observed for $\mathrm{PdCl}_{2}(\mathrm{PhCN})_{2}$ at $80{ }^{\circ} \mathrm{C}$ for $20 \mathrm{~h}$ (entry 6). The thorium catalyst shows a similar trend although with lower selectivity (entry 10). On the other hand, gold-based catalytic systems exhibit complete $E$ selectivity (entry 19-20), whereas copper species favor $Z$-selectivity 
(entries 21-22). Rhodium complexes show a chameleonic behavior that depends markedly on the ligands involved. Thus, Wilkinson's catalyst gives rise to the $E$-vinyl sulfide with complete selectivity (entry 16) whereas $\mathrm{Tp} * \mathrm{Rh}\left(\mathrm{PPh}_{3}\right)_{2}$ favors the Markovnikov derivative (entry 15). More surprising is the performance of rhodium catalysts containing $\mathrm{N}$-heterocyclic carbene (NHC) ligands where the simple addition of pyridine switches the selectivity completely from $\beta$ - to $\alpha$-vinyl sulfides (entries 17-18) under mild conditions.

Table 1. Hydrothiolation of phenylacetylene with thiophenol promoted by selected catalytic systems.

\begin{tabular}{|c|c|c|c|c|c|c|}
\hline Entry & Catalyst & Solvent & $(\mathrm{C} g / \mathrm{t}(\mathrm{h})$ & Yield(\%) & $(\beta-Z / \beta-E / \alpha)$ & Ref. \\
\hline 1 & none & THF & $25 / 30$ & 90 & $80 / 20 / 0$ & $20 \mathrm{a}$ \\
\hline 2 & Silica nanoparticles & none & r.t./0.5 & 96 & $40 / 60 / 0$ & 32 \\
\hline 3 & $\mathrm{Cs}_{2} \mathrm{CO}_{3}(\mathrm{TEMPO})$ & DMSO & $85 / 4$ & 14 & $88 / 12 / 0$ & $9 d$ \\
\hline 4 & $\mathrm{Mn}(\mathrm{OAc})_{3} \cdot 2 \mathrm{H}_{2} \mathrm{O}$ & $\mathrm{CH}_{3} \mathrm{CO}_{2} \mathrm{H}$ & $118 / 0.03$ & 98 & $10 / 90 / 0$ & $25 a$ \\
\hline 5 & $\mathrm{InBr}_{3}$ & $\mathrm{CH}_{2} \mathrm{Cl}_{2}$ & r.t./0.42 & 96 & $30 / 70 / 0$ & $24 b$ \\
\hline 6 & $\mathrm{PdCl}_{2}(\mathrm{PhCN})_{2}$ & $\mathrm{C}_{6} \mathrm{H}_{6}$ & $80 / 20$ & 68 & $0 / 0 / 100$ & $14 \mathrm{c}$ \\
\hline 7 & $\begin{array}{l}\mathrm{PdCl}_{2}\left[\mathrm{P}\left(\mathrm{NC}_{5} \mathrm{H}_{10}\right)\right. \\
\left.\left(\mathrm{C}_{6} \mathrm{H}_{11}\right)_{2}\right]_{2}(\mathrm{NaOH})\end{array}$ & NMP & $120 / 0.25$ & 99 & $99 / 1 / 0$ & $14 \mathrm{j}$ \\
\hline 8 & $\begin{array}{l}\mathrm{NiCl}_{2}(\gamma \text {-terpinene; } \\
\left.\mathrm{Et}_{3} \mathrm{~N}\right)\end{array}$ & $\mathrm{CHCl}_{3}$ & $80 / 5$ & 27 & $(77)^{[\mathrm{a}]} / 23$ & $16 b$ \\
\hline 9 & $\mathrm{Ni}(\mathrm{acac})_{2}$ & None & $40 / 0.13$ & 82 & $(27)^{[\mathrm{a}]} / 73$ & $16 c$ \\
\hline 10 & $\begin{array}{l}\mathrm{Cp}_{2}{ }_{2} \mathrm{Th}\left(\mathrm{CH}_{2} \mathrm{TMS}\right)_{2} \\
(\gamma \text {-terpinene })\end{array}$ & $\mathrm{C}_{6} \mathrm{D}_{6}$ & $120 / 16$ & 61 & $(17)^{[\mathrm{a}]} / 83$ & $28 b$ \\
\hline 11 & {$\left[\operatorname{lr}(\operatorname{ImP} 1 \mathrm{a})(\mathrm{CO})_{2}\right] \mathrm{BPh}_{4}$} & $\mathrm{CDCl}_{3}$ & r.t./17 & 93 & $74 / 26 / 0$ & $20 b$ \\
\hline 12 & {$\left[\operatorname{lr}(\mathrm{PyP})(\mathrm{CO})_{2}\right] \mathrm{BPh}_{4}$} & $\mathrm{CDCl}_{3}$ & $25 / 3.3$ & 96 & $90 / 10 / 0$ & $20 a$ \\
\hline 13 & {$\left[\mathrm{Rh}(\mathrm{PyP})(\mathrm{CO})_{2}\right] \mathrm{BF}_{4}$} & $\mathrm{CDCl}_{3}$ & $25 / 7.1$ & 94 & $71 / 29 / 0$ & $20 a$ \\
\hline 14 & Rh-P-SBA-15 & DCE & r.t./20 & 87.5 & $0 / 99 / 1$ & $19 f$ \\
\hline 15 & $\mathrm{Tp}^{*} \mathrm{Rh}\left(\mathrm{PPh}_{3}\right)_{2}$ & $\begin{array}{l}\text { DCE:Tol } \\
(1: 1)\end{array}$ & r.t./2 & 84 & $0 / 14 / 86$ & $19 a$ \\
\hline 16 & $\mathrm{RhCl}\left(\mathrm{PPh}_{3}\right)_{3}$ & $\mathrm{EtOH}$ & $40 / 20$ & 97 & $0 / 100 / 0$ & $14 \mathrm{c}$ \\
\hline 17 & {$\left[\mathrm{RhCl}(\mathrm{IPr})\left(\mathrm{C}_{2} \mathrm{H}_{4}\right)\right]_{2}$} & $\mathrm{C}_{6} \mathrm{D}_{6}$ & r.t./ 0.4 & 99 & 0/67/33 & $19 i$ \\
\hline 18 & $\begin{array}{l}{\left[\mathrm{RhCl}(\mathrm{IPr})\left(\mathrm{C}_{2} \mathrm{H}_{4}\right)\right]_{2}} \\
\text { (10eq. pyridine) }\end{array}$ & $\mathrm{C}_{6} \mathrm{D}_{6}$ & r.t./7 & 99 & 0/6/94 & $19 i$ \\
\hline 19 & {$\left[\mathrm{Au}^{\prime}(\mathrm{NHC})\right]^{+}$} & toluene & $40 / 0.17$ & 100 & $0 / 100 / 0$ & $22 c$ \\
\hline 20 & $\mathrm{Au}^{\prime \prime \prime \prime}(\mathrm{NHC})(\mathrm{MCM}-41)$ & toluene & $40 / 1$ & 100 & $0 / 100 / 0$ & $22 c$ \\
\hline 21 & $\mathrm{Cul}\left(\mathrm{Et}_{3} \mathrm{~N}\right)$ & none & $40 / 4$ & 100 & $100 / 0 / 0$ & $21 f$ \\
\hline 22 & $\mathrm{Cul}\left(\mathrm{K}_{2} \mathrm{CO}_{3} ; \mathrm{H}_{2} \mathrm{O} ; \mathrm{CO}_{2}\right)$ & DMSO & $90 / 16$ & 92 & $91 / 9 / 0$ & $21 \mathrm{e}$ \\
\hline
\end{tabular}

[a] No $E / Z$ selectivity reported.

\section{Non Metal-Mediated Hydrothiolation}

Although the radical pathway was the first method implemented, this fact was not entirely recognized at the time. ${ }^{[6 a]}$ The weakness and low polarity of S-H bonds facilitate their homolytic cleavage to generate a thiyl radical, especially in the case of aromatic thiols. This reaction requires the presence of an initiator or UV-visible irradiation and is generally very fast and regioselective for the antiMarkovnikov products, although lacks for stereoselectivity (Scheme 1). Indeed, the radical-initiated coupling between an alkene and a thiol has been claimed to fulfil the requirements to be considered a "click" reaction. ${ }^{[3,30]}$ The regioselectivity outcome is governed by the stability of the new carboradical formed, generally the more substituted one, and thus the sulfur atom adds to the terminal carbon atom. However, it is problematic to inhibit the formation of byproducts such as disulfide or the oligomerization of unsaturated substrates. An additional drawback in the particular case of alkyne hydrothiolation is the double addition of the thiol, as radicals react faster with the intermediate vinyl sulfide than with the starting alkyne, except for aromatic substrates. ${ }^{[7 a]}$ In any case, radical processes could find important applicability in materials science or biomolecular chemistry, where selectivity is not a critical requisite.

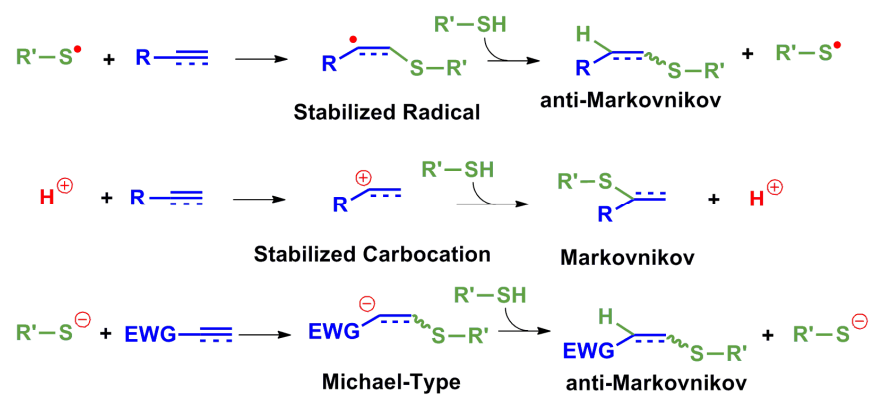

Scheme 1. Non-metal mediated hydrothiolation reactions.

Contrary to radical processes, acid-promoted hydrothiolation gives access to Markovnikov-type compounds, with the more stable carbocation dictating product formation. Nevertheless, the drastic conditions generally required often produce decomposition or polymerization of the starting material. The selectivity of basepromoted transformations, where steric factors play an important role, is more complex, with the base enhancing the nucleophilicity of the sulfur atom, thereby facilitating nucleophilic addition. However, this strategy is limited to aromatic-substituted unsaturated substrates or those activated for Michael-type additions, and sometimes requires a stoichiometric amount of base. ${ }^{[31]}$ More recently, several methods, including the use of zeolites, ${ }^{[32]}$ nanoparticles, ${ }^{[33]}$ ionic liquids, ${ }^{[34]}$ and other supports have been developed, especially for alkynes, in an attempt to improve the recyclability of the reaction. ${ }^{[35]}$ In this respect, special attention has been paid to the use of water as a green solvent in hydrothiolation. ${ }^{[36]}$ The first report stated that $\beta$-cyclodextrin is an essential additive in order to obtain the coupling products. ${ }^{[36 a]}$ However, subsequent studies showed that promoters are not required. ${ }^{[36 \mathrm{~b}-\mathrm{c}]}$ It has been suggested that both $\beta$-cyclodextrin and water increase the nucleophilic character of the thiol, although a radical mechanism cannot be ruled out, as the catalytic runs were carried out in the dark but without excluding dioxygen from the solvent, which is known to be a radical promoter. Indeed, in a more recent contribution it is proposed that the vicinal double addition of aliphatic thiols to alkynes proceeds via water-stabilized radicals. ${ }^{[36 \mathrm{~d}]}$ In any case, the practical use of water as a solvent for these transformations paves the way for new and interesting reactions, thus meaning that an in-depth understanding of the mechanism is highly desirable.

\section{Metal-Mediated Transformations}

Several different metallic compounds have proven to be highly useful for the hydrothiolation of unsaturated bonds and exhibit a broad range of catalytic or initiation pathways. Metal-mediated transformations constitute an exciting alternative to radical or ionic processes, especially as regards controlled selectivity for the Markovnikov-type compounds under mild reaction conditions. In general, the reactivity of non-activated substrates is increased in the presence of a metal species, with lower by-product formation. Another interesting advantage is the clean preparation of vinyl sulfides with no concomitant formation of dithioacetals as a result of double addition of the thiol to the alkyne. However, the prevalence of non-catalytic pathways for hydrothiolation sometimes makes it difficult to clearly identify a new catalytic route promoted by metallic species as several reaction pathways may be followed simultaneously. In order to more clearly present the data reported in this field, we have organized the catalytic mechanistic information 
available into four subsections: $i$ ) non-coordination metal-promoted catalytic systems, ii) metal activation of the unsaturated substrates, iii) metal activation of the thiol, and $i v$ ) rhodium-based catalysts. Certainly, the proposed classification is not particularly strict as the catalytic results can be interpreted in several different ways, especially those where activation of the substrates is involved, as both reactants are "activated" for coupling in some cases. Finally, rhodium-based catalytic systems are described separately due to their versatility and diversity as regards their catalytic pathways.

\subsection{Metal-mediated transformations with no substrate coordination.}

Some metallic salts behave as promoters for the hydrothiolation of unsaturated compounds with no direct coordination of the substrates (Scheme 2). For example, $\mathrm{Mn}^{\mathrm{III}}$ salts are good radical initiators, thus meaning that the reaction may proceed as described previously in terms of both activity and selectivity. ${ }^{[25]}$ Interestingly, other main group metal salts, such as those of aluminium or indium, promote Markovnikov-type additions. ${ }^{[13-24]}$ It has been proposed that the metal favours the formation of superacid species in these cases, thus following a carbocation-intermediate pathway. Alkynes behave somewhat differently to olefins in these catalytic systems. It has been reported that Markovnikov-type vinyl sulfides are generally obtained with heteroaromatic thiols whereas a mixture of $Z / E$ vinyl thioethers is obtained for aliphatic or aromatic ones. ${ }^{[24 \mathrm{~d}]}$ It should be expected that the more acidic heteroaromatic thiols are prone to interact more easily with the indium salt to form superacid species, thereby generating gem-vinyl sulfides. However, the formation of anti-Markovnikov addition products from the less acidic thiols remains unexplained. In this context, it is worth mentioning that the Lewis acid character of In $^{\mathrm{III}}$ compounds could lead to activation of the alkyne, thiol, or both, to nucleophilic attack (see below). A remarkable result achieved by these catalysts is their ability to form dithioacetals with Markovnikov-type selectivity in the case of aliphatic alkynes, which is the opposite to that observed for radicalmediated processes. ${ }^{[24 \mathrm{~b}]}$

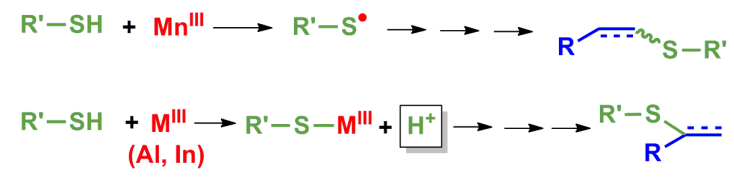

Scheme 2. Metal-mediated hydrothiolation with no direct coordination.

\subsection{Activation of the unsaturated substrate by organometallic catalysts}

It is well-documented that transition metal species may act as Lewis acids to activate unsaturated compounds for nucleophilic attack (Scheme 3). Amongst these, gold catalysts have recently received a great deal of attention due to the soft and carbophilic nature of this metal, which especially favours the activation of alkynes. ${ }^{[37]}$ Alkenes, alkynes or allenes have been subjected to hydrothiolation with a preferred Markovnikov selectivity inferred from $\pi$-activation. ${ }^{[22]} \mathrm{A}$ reverse regioselectivity was observed for gold species bearing an electron-rich ligand where enhancement of the nucleophilicity of the thiol favors a competitive pathway (see below for examples of copper complexes). ${ }^{[22 c]} \mathrm{A}$ rare example of intramolecular hydrothiolation of an $\alpha$-thioallene promoted by gold species has been described recently. ${ }^{[22]}$ The double addition of aromatic thiols to allenes is also remarkable. ${ }^{[22 \mathrm{~d}]}$ Interestingly, thioacetals were found to be in equilibrium with the intermediate vinyl sulfides therefore, the chemoselectivity can be controlled by adjusting the catalyst loading or reaction temperature.<smiles></smiles><smiles>[R]OC(=O)C#CC([R20])S</smiles><smiles>[R]C1CC2([R])CC([R])(C1)S[Si]2</smiles>

Scheme 3. $\pi$-Bond activation for nucleophilic attack.

An alternative mode of $\pi$-activation was proposed for molybdenum species in one of the earliest examples of transition metal-mediated hydrothiolation. ${ }^{[1]}$ The ester-coordination of an acetylene diester substrate reduces the electronic density on the alkyne, thus enhancing nucleophilic attack of the thiol. However, it is clear that metal species could also increase the nucleophilicity of the thiol. Indeed, it has been proposed that iron catalysts are able to interact with both the alkyne and the thiol, thereby reducing the energy barrier for the coupling (Scheme 3) ${ }^{[18]}$ In this context, copper-based catalytic systems are a particular case where activation of both the alkyne $\mathrm{e}^{[21 \mathrm{e}-\mathrm{f}]}$ and the thiol ${ }^{[21 \mathrm{a}-\mathrm{c}]}$ is thought to be the key step in this reaction. The selective formation of $Z$ - $\beta$-vinylsulfides from propiolic acids is somewhat more controversial (Scheme 4). ${ }^{[21 d-f]}$ An early work by Liu and coworkers reported the decarboxylative formation of vinyl sulfides with high Zstereoselectivity. ${ }^{[21 \mathrm{~d}]}$ More recently, a related study with a copperbased catalytic system has shown that the presence of $\mathrm{CO}_{2}$ and water is essential for the observed $Z$-selectivity. Indeed, it has been proposed that the terminal alkyne reacts with carbon dioxide to form a propiolic acid and therefore, to ensure Z-selectivity, the copper center must simultaneously activate the triple bond, the ester moiety, as discussed previously for molybdenum, the thiol, and one molecule of water. ${ }^{[21 \mathrm{e}]}$ In contrast, Beletskaya et al. have reported the selective formation of the $Z$-vinyl sulfide from thiophenol and phenylacetylene in the presence of $\mathrm{NEt}_{3}$ with copper iodide as catalyst. ${ }^{[21 \mathrm{f}]}$ It has also been showed that copper species favour the $Z \rightarrow E$ isomerization of the vinyl thioether, thus suggesting that decarboxylation most probably occurs prior to hydrothiolation and that the $\mathrm{CO}_{2}$ may play an active role in preventing isomerization of the vinyl sulfide. Certainly, the evident interest of this stereoselective transformation would require a thorough mechanistic investigation.

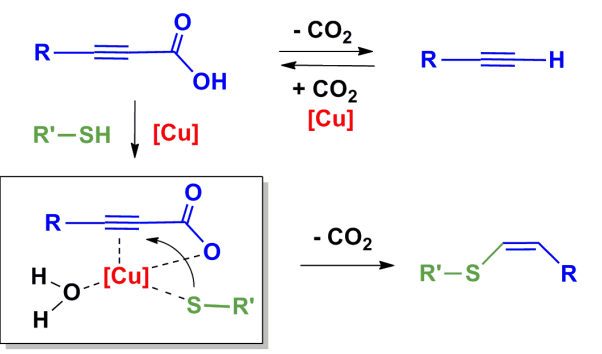

Scheme 4. Copper-catalyzed Z-selective preparation of vinyl sulfides. 
Palladium-based catalysts usually activate the thiol for migratory insertion (see below), although an exception has been encountered for the hydrothiolation of 1-alkynylphosphines. ${ }^{[14 \mathrm{e}]} \mathrm{In}$ order to explain the unique anti-addition of the thiol in this case, preliminary coordination of the phosphine group to palladium, thus favoring external attack of the thiol in an anti-manner, has been suggested (Scheme 5). Moreover, Gabriele, Salerno et al. have proposed that $\mathrm{PdI}_{2}$ activates the triple bond of several enyne mercaptans to intramolecular attack of the thiol to form cycloisomerized thiophenes. ${ }^{[14 \mathrm{~d}]}$

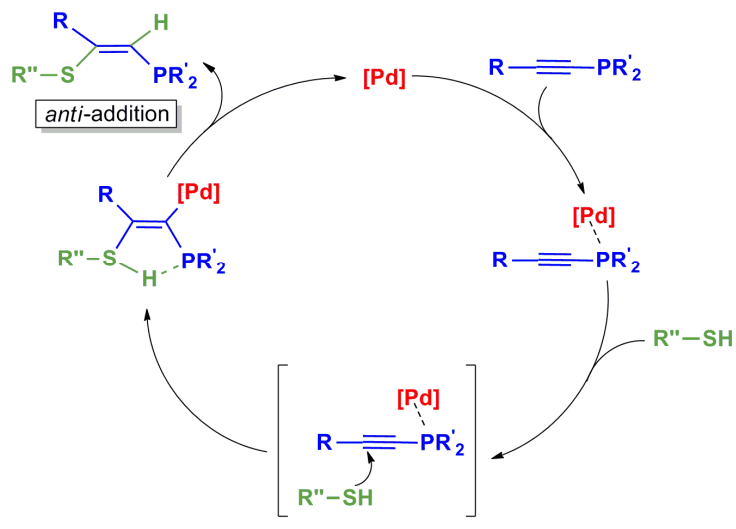

Scheme 5. Palladium-catalyzed hydrothiolation of 1alkynylphosphines.

Another classical mode of activation for terminal alkynes involves the formation of metal-vinylidene species. ${ }^{[38]}$ In these cases, the thiol attacks the electrophilic $\alpha$-carbon of the cumulene to selectively provide the anti-Markovnikov products. Interestingly, the possible involvement of a dinuclear intermediate has been proposed in the hydrothiolation of methylpropiolate mediated by $[\mathrm{Cp} * \mathrm{Ru}(\mathrm{SR})]_{2}$, although other possibilities could not be discarded (Scheme 6). ${ }^{[17]}$

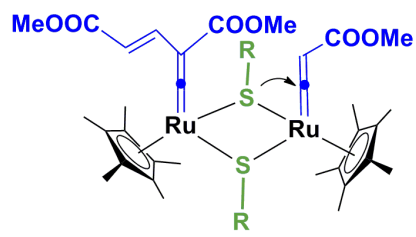

Scheme 6. Alkyne hydrothiolathion via dinuclear rutheniumvinylidene intermediates.

\subsection{Activation of the thiol by organometallic catalysts}

Activation of the thiol by organometallic species is by far the most common approach for hydrothiolation. Two main pathways appear to be operative in this reaction: an acid-base reaction that gives rise to thiolate complexes (Scheme 7), or oxidative addition of the thiol to generate hydride-thiolate derivatives (Scheme 8). In the first case the reaction may follow two alternative routes, namely external nucleophilic attack of the thiolate at the unsaturated molecule or insertion of the unsaturated substrate into metal-thiolate bonds. ${ }^{[39]}$ Subsequent addition of a proton from a new thiol molecule gives rise to the organic products and regenerates the metal-thiolate species.

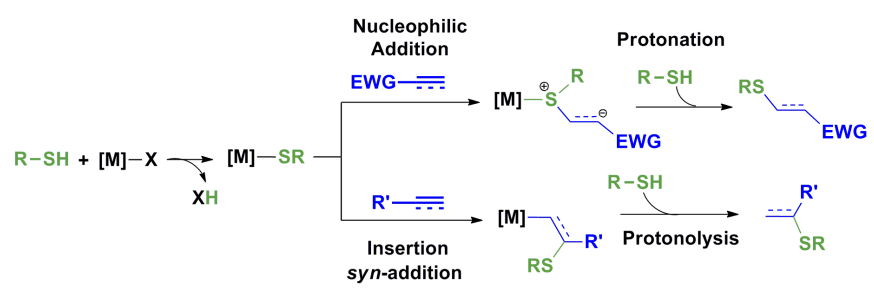

Scheme 7. Acid-base metal-mediated thiol activation.

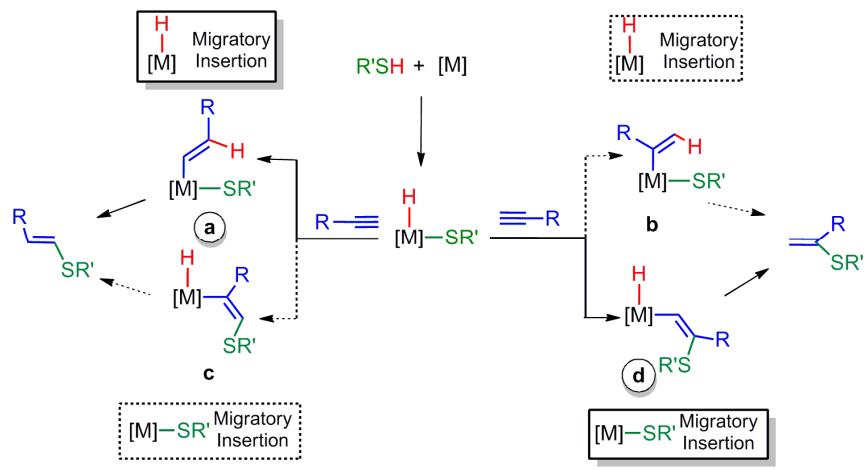

Scheme 8. Pathways for alkyne insertion into M-H or M-SR bonds.

In the particular case of alkyne hydrothiolation via migratory insertion and subsequent reductive elimination, both steps may be determinant for the regioselectivity (Scheme 8). ${ }^{[40]}$ Kinetically speaking, the formation of linear metal-alkenyls via 1,2-insertion (a,d) is electronically and sterically preferred to that of branched isomers via 2,1 insertion (b,c). ${ }^{[41]}$ Thus, if migratory insertion is the rate-determining step, the type of insertion governs the selectivity: insertion into a metal-hydride bond (a) gives rise to linear thioethers whereas insertion into metal-thiolate bonds (d) generates branched or Markovnikov-type vinyl sulfides. As insertion into metal-hydride bonds is favoured with regard to that into their metal-thiolate counterparts, ${ }^{[14 c, 42]}$ a process that directs alkyne insertion into metalthiolate bonds would need to be designed in order to ensure selective preparation of the less accessible branched vinyl sulfides in a controlled manner.

The migratory insertion process is favored for alkynes over olefins and the addition usually proceeds in a syn-fashion, although some Pt complexes give the anti-addition products under photolytic conditions. ${ }^{[42,43]}$ One important issue is the acidity of the thiol component, which could have a marked effect on the activity of this type of substrate with different metallic catalysts. In general, the more acidic aromatic thiols favor oxidative addition or protonolysis, whereas aliphatic thiols increase the insertion rates.

A representative example of the first route from Scheme 7 has been reported by Gunnoe and coworkers, ${ }^{[21 \mathrm{a}-\mathrm{b}]}$ who proposed that coordination of an N-heterocyclic carbene ligand in copper-thiolate species enhances the ability of the thiolate ligand to nucleophilically attack activated or aromatic olefins, thus leading to the antiMarkovnikov products. Although the selectivity is similar to that obtained in a simple base-catalyzed reaction, it is expected that modification of the ancillary ligands on the copper catalyst precursor would allow the activity to be increased and open the door to enantioselectivity. 


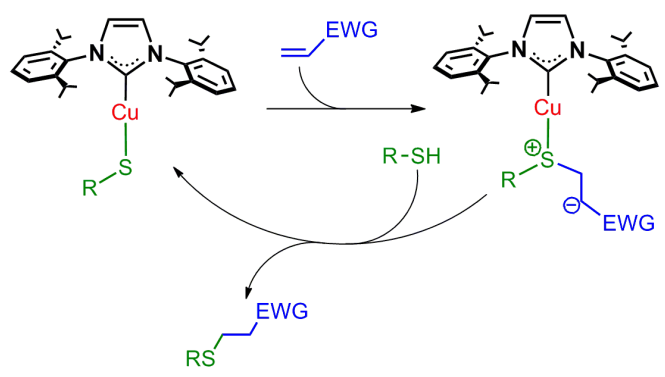

Scheme 9. Thiol activation by copper-NHC catalysts.

Ogawa's group pioneered the emergence of transition metal species as catalysts for alkyne hydrothiolation, with their seminal paper in $1992,{ }^{[14 a]}$ confirming the ability of metal catalysts to perform C-S coupling efficiently. Markovnikov-vinyl sulfides were prepared selectively using $\mathrm{Pd}(\mathrm{OAc})_{2}$ as catalyst precursor. In this particular case, the exclusive presence of thiolate ligands in the catalytically active species, with no hydride ligands, determines the insertion type and fully accounts for the observed selectivity. However, this is not a general mechanism as other $\mathrm{Pd}^{0}$ precatalysts show no such selectivity. The formation of bis-thioalkenes or the isomerization of $\alpha$-vinyl sulfides to internal olefins has also been observed in the case of aliphatic alkynes, especially for the catalyst $\mathrm{Pd}(\mathrm{PhCN})_{2} \mathrm{Cl}_{2}$. Beletskaya, Ananikov et al. subsequently proposed that the actual catalytic species formed by reaction of the palladium precursors with the thiol are oligomeric or polymeric thiolatespecies. ${ }^{[14 f]}$ Indeed, the formation of this polymeric species does not require the presence of an internal base, as in the case of $\mathrm{Pd}(\mathrm{OAc})_{2}$. Furthermore, it has been demonstrated that the same polymeric species can be obtained from $\mathrm{Pd}\left(\mathrm{PPh}_{3}\right)_{4}$ by consecutive addition of two molecules of thiol and concomitant release of molecular hydrogen (Scheme 10). ${ }^{[16 b]}$

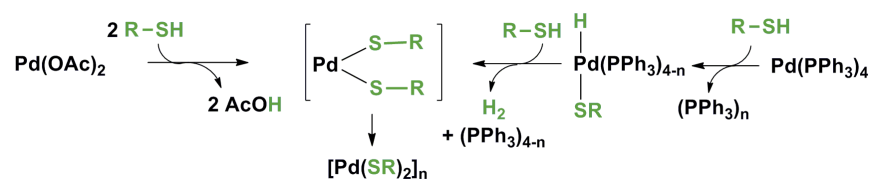

Scheme 10. Activation of palladium precatalysts by thiol reagents.

Further work with palladium catalysts has shown that the presence of water in the catalytic reaction medium enhances double hydrothiolation of the alkyne to selectively form Markonikov dithioketals. ${ }^{[14 h]}$ It has been proposed that water may accelerate the protonolysis step during the addition of a second molecule of thiol to the vinyl sulfide intermediate. Very recently, an unexpected influence of the substituents on the alkyne on the regioselectivity has been observed for a catalytic system based on $\left[\mathrm{Pd}\left(\mathrm{P}\left(\mathrm{NC}_{5} \mathrm{H}_{10}\right)\left(\mathrm{C}_{6} \mathrm{H}_{11}\right)_{2}\right)_{2} \mathrm{Cl}_{2}\right]$ and $\mathrm{NaOH}$ at $120^{\circ} \mathrm{C}$ (Scheme 11)..$^{[14 \mathrm{j}]}$ Aromatic alkynes give rise to $Z$ - $\beta$-vinyl sulfides, whereas aliphatic alkynes generate Markovnikov derivatives. It has been proposed that the palladium catalyst may act as a $\pi$-alkyne activator for external attack of the thiol in the case of aromatic alkynes, whereas migratory insertion occurs for aliphatic ones. More research into the mechanistic understanding of this interesting effect should prove highly valuable.

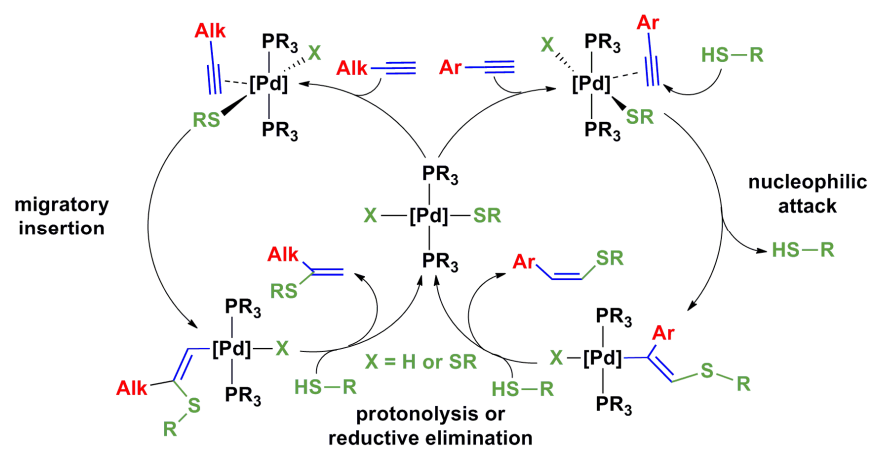

Scheme 11. Discrimination between aliphatic or aromatic alkynes in palladium-mediated hydrothiolation.

Nickel catalysts represent a cheaper alternative to palladium catalysts. ${ }^{[16]}$ The simple catalytic system $\mathrm{NiCl}_{2}+\mathrm{NEt}_{3}$ was found to reduce isomerization to internal vinyl sulfides at low temperature, whereas it is necessary to work with an excess of thiol in order to reduce alkyne oligomerization. ${ }^{[16 b]}$ In general, the insertion mechanism prevails over external nucleophilic attack, as nicely demonstrated for the hydrothiolation of internal alkynes using $\mathrm{Ni}(\mathrm{acac})_{2}$ as catalyst precursor (Scheme 12). ${ }^{[16 \mathrm{cc}}$ Indeed, there is strong evidence for the formation of polymeric species of the type $\left[\mathrm{Ni}(\mathrm{SPh})_{2}\right]_{\mathrm{n}}$, thus meaning that catalysis is likely to proceed via an alkyne insertion-protonolysis sequence. A further improvement in catalyst design involves the use of $\mathrm{CpNi}(\mathrm{NHC}) \mathrm{Cl}$ as strictly homogeneous catalysts. Mechanistic studies under catalytic conditions have revealed the participation of monothiolate organometallic species as intermediates in the catalytic cycle. These species were obtained by treatment of chloride complexes with thiols in the presence of $\mathrm{NEt}_{3}$. Interestingly, the formation of bisthioalkenes and isomerization products is suppressed with this catalytic system.

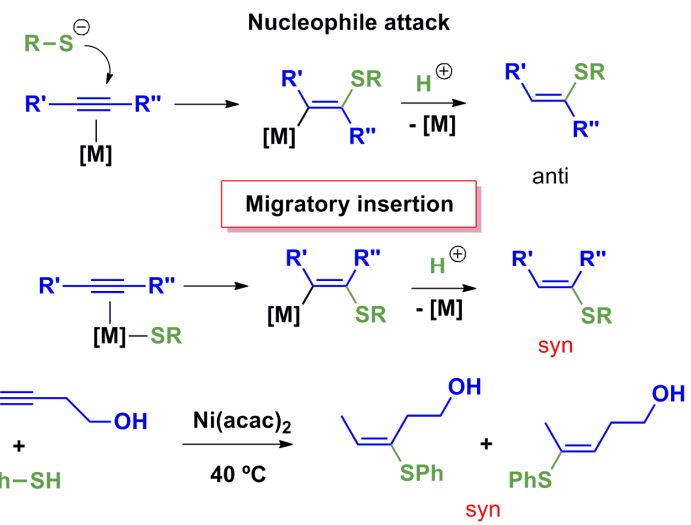

Scheme 12. Confirmation of a migratory insertion mechanism operating for the catalytic system based on the $\mathrm{Ni}(\mathrm{acac})_{2}$ precursor.

Another relevant example of Markovnikov-selective catalysts based on group 4, lanthanide, or actinide metal precursors has been reported by the Marks group (Scheme 13). ${ }^{[27,28]}$ These catalytic systems present a great versatility as regards the substituents on both the thiol and the alkyne. These authors carried out extensive and detailed mechanistic studies and calculated the thermodynamic parameters for the different intermediate reactions. Based on kinetic data, they found that the reaction proceeds via an alkyne insertionthiol protonolysis mechanism, with the former being the ratedetermining step. The applicability of these catalytic systems has 
been demonstrated by a recently published international patent application. ${ }^{[4]}$

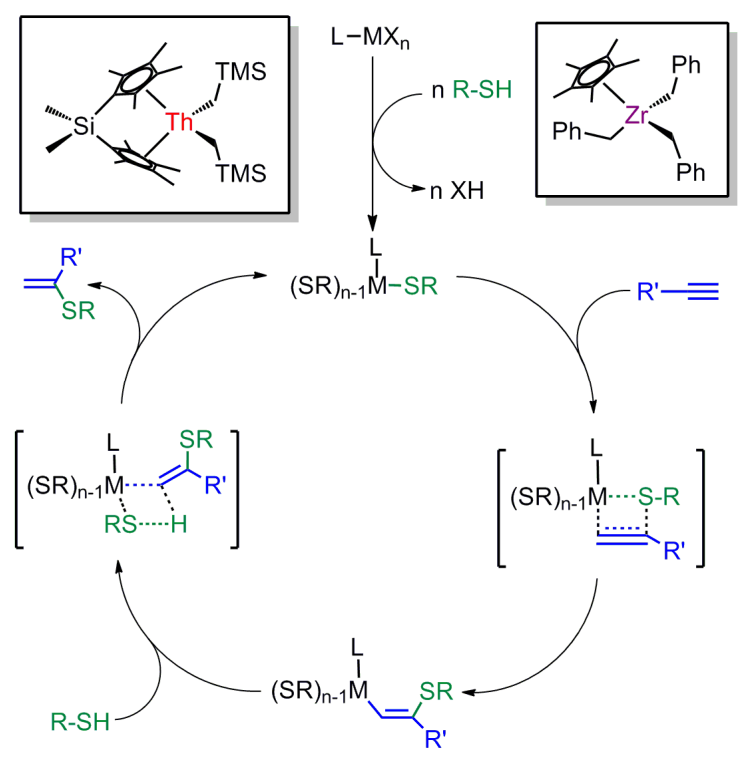

Scheme 13. Organometallic catalyst precursors for alkyne hydrothiolation with Markovnikov selectivity.

Messerle and coworkers have shown that iridium complexes may act as efficient catalysts for alkyne hydrothiolation (Scheme 14). ${ }^{[20]}$ Neutral and cationic derivatives bearing a range of bidentate ligands were studied. The best results were obtained for cationic complexes having P,N bidentate ligands which showed complete selectivity for the $E / Z$ anti-Markovnikov vinylsufide products. Mechanistic investigations ${ }^{[45]}$ point to a catalytic cycle initiated by oxidative addition of the thiol to generate hydride-thiolate species followed by alkyne insertion into the hydride ligand. The formation of $\mathrm{Z}$ - $\beta$-vinyl sulfide would require an isomerization of metal-alkenyl intermediates prior to reductive elimination step. ${ }^{[46]}$

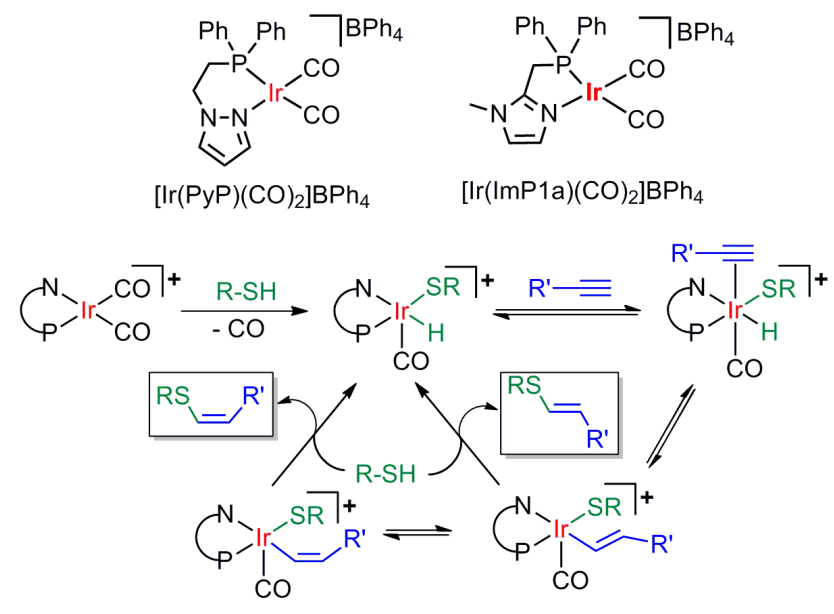

Scheme 14. Iridium catalysts favouring anti-Markovnikov selectivity.

\subsection{Rhodium catalysts as chameleonic species}

Rhodium complexes constitute a special case within the field of hydrothiolation catalysts by behaving as chameleonic species that give different selectivities upon subtle modifications to their ancillary ligands. ${ }^{[47]}$ The crux of the matter is that, in contrast to other metals such as $\mathrm{Pd}$ or Ni where, as discussed previously, only thiolate ligands remain on the active species, unsaturated rhodium species oxidatively add thiols to give hydride-thiolate species, thus allowing for ligand-based control of the alkyne insertion into metalhydride or metal-thiolate bonds, which in turn determines the regioselectivity (Scheme 15). Two facts have to be considered in this respect: $i$ ) the energy barrier for alkyne insertion is lower for metal-hydride bonds than metal-thiolate bonds, thereby favoring anti-Markovnikov selectivity, and ii) the high trans influence of the hydride directs the coordination of the alkyne in the trans position to the hydride (and cis to the thiolate ligand), thereby generating Markovnikov products. A complex interplay between these two effects is likely to account for the regioselectivity. In general terms, anti-Markovnikov products should be obtained for catalysts with low stereochemical control within the active species or those favoring a trigonal bipyramidal structure, as would be the case for compounds $\mathrm{RhCl}\left(\mathrm{PPh}_{3}\right)_{3},{ }^{[14 \mathrm{c}, 19 \mathrm{~d}, \mathrm{i}]} \quad\left[\mathrm{Rh}(\mathrm{PyP})(\mathrm{CO})_{2}\right] \mathrm{BF}_{4},{ }^{[20 \mathrm{a}]}$ or $\left[\mathrm{RhCl}(\mathrm{NHC})\left(\eta^{2} \text {-olefin }\right)\right]_{2},{ }^{[19 i]}$ whereas catalysts of the type $\mathrm{Tp} * \mathrm{Rh}\left(\mathrm{PPh}_{3}\right)_{2}{ }^{[19 \mathrm{a}, \mathrm{e}]}$ or $\mathrm{RhCl}(\mathrm{NHC})(\mathrm{py})\left(\eta^{2} \text {-olefin }\right)^{[19 \mathrm{i}]}$ promote alkyne insertion into metal-thiolate bonds, thereby opening the way to the design of more active and specific catalysts.

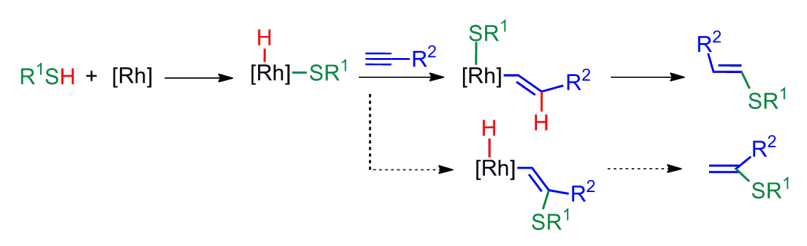

High trans-influence of the hydride $\Longrightarrow$ Ligand-control of alkyne coordination

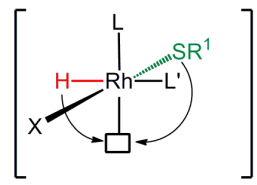

anti-Markovnikov or Not Selective

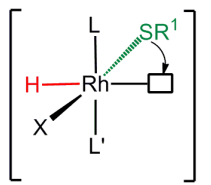

Markovnikov
Scheme 15. Ligand control over alkyne coordination in rhodium catalysts.

The mechanism for Wilkinson's catalyst has been studied by Ogawa's group in stoichiometric NMR experiments (Scheme 16). ${ }^{[14 c]}$ These authors found that oxidative addition of thiophenol leads to formation of the pentacoordinate complex trans$\mathrm{HRhCl}(\mathrm{SPh})\left(\mathrm{PPh}_{3}\right)_{2}$, which, based on the ${ }^{1} \mathrm{H}$ NMR hydride chemical shift (-16.4 ppm) and small $J_{\mathrm{Rh}-\mathrm{H}}$ of $19 \mathrm{~Hz}$, most likely has a trigonal bipyramidal structure. ${ }^{[48]}$ Subsequent addition of 1-dodecyne yields a stable metal-alkenyl complex resulting from insertion into the Rh$\mathrm{H}$ bond. An excess of thiophenol gives the vinyl sulfide with antiMarkonikov selectivity. Furthermore, based on deuterium labeling experiments, Love et al. have also demonstrated alkyne insertion into the metal-hydride intermediate, thereby ruling out a possible competing vinylidene-based pathway. ${ }^{[19 \mathrm{~d}]}$ More recently, supported catalysts based on $\mathrm{RhCl}\left(\mathrm{PR}_{3}\right)_{3}{ }^{[19 f, \mathrm{~h}]}$ or the application into the synthesis of polymers with optical properties ${ }^{[19 \mathrm{~g}]}$ have been reported. Interestingly, the substitution of a phosphine ligand in $\mathrm{RhCl}\left(\mathrm{PPh}_{3}\right)_{3}$ by an N-heterocyclic carbene increases the stability of the catalytic species whilst slightly diminishing the initial rate. ${ }^{[19 i]}$ 


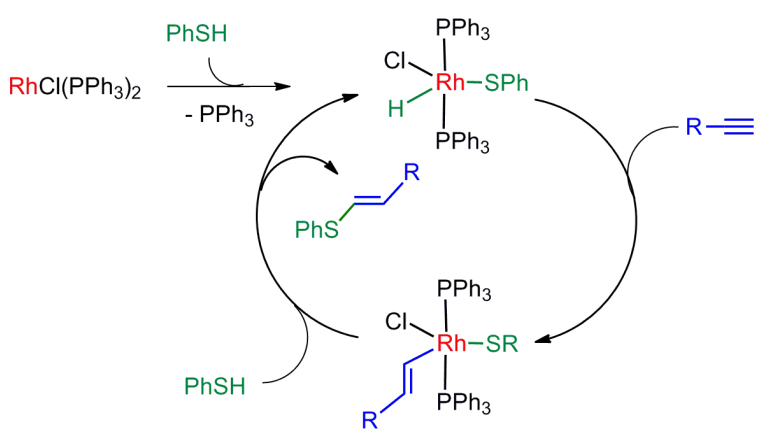

Scheme 16. Catalytic cycle proposed for Wilkinson's catalyst.

Another milestone in hydrothiolation reactions was reported in 2005 by Love's group. ${ }^{[19 a]}$ Contrary to the expectation at that time that group 9 transition metal-based catalysts induce antiMarkovnikov selectivity, these authors elegantly showed that branched vinyl sulfide compounds could be obtained by the introduction of a hydrotris(3,5-dimethylpyrazolyl)borate ligand $(\mathrm{Tp} *)$ in rhodium precursors. Furthermore, $\mathrm{Tp} * \mathrm{Rh}\left(\mathrm{PPh}_{3}\right)_{2}$ complexes are very active, especially as regards the previously unreactive aliphatic thiols. Remarkably, this catalytic system exhibits a broad scope as the catalytic activity is maintained in the presence of a broad range of functional groups such as amines, ethers, nitriles or silanes. The influence of the structure of the Tp moiety has also been studied and the bis(pyrazolyl)borate precursor found to be less effective than the tris(pyrazolyl)borate analogs, thus indicating that the ability of the ligand to adopt $\kappa^{3}$-coordination is essential. Substitution in the 3- and 5- positions is also very important. A spectroscopic study of the reaction suggested a complex mechanism that has not yet been fully determined. However, selective alkyne insertion into Rh-S bonds in the presence of a hydride ligand has been proposed (Scheme 17). ${ }^{[49]}$

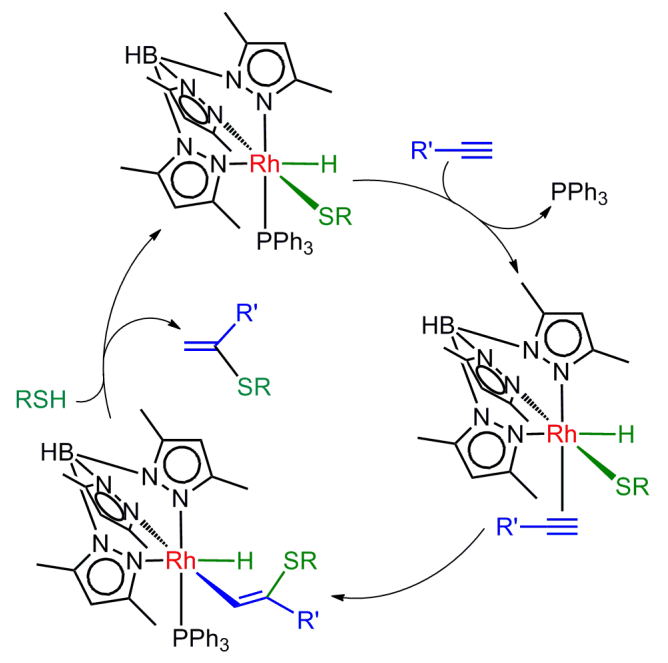

Scheme 17. Proposed catalytic cycle for $\mathrm{Tp} * \mathrm{Rh}\left(\mathrm{PPh}_{3}\right)_{2}$ leading to Markovnikov-vinyl sulfides via alkyne Rh-S insertion.

A year after the first report concerning the catalytic activity of $\mathrm{Tp} * \mathrm{Rh}\left(\mathrm{PPh}_{3}\right)_{2}$, Mizobe and co-workers showed that the related complex $\mathrm{Tp} * \mathrm{Rh}(\mathrm{coe})(\mathrm{MeCN})$ (coe $=\eta^{2}$-cyclooctene) promotes the hydrothiolation of benzyl and phenylacetylene with thiophenol. However, a different mechanism to that of Love's phosphinecontaining catalyst was proposed (Scheme 18). Thus, a double addition of thiophenol with release of molecular hydrogen should give rise to a dithiolate-rhodium complex as the active species. Insertion of the alkyne into an Rh-S bond is therefore the only possibility, thus generating $\alpha$-vinyl sulfides by subsequent protonolysis, as described previously for palladium or zirconium catalysts. This mechanistic proposal is strongly supported by reactivity studies and the X-ray structural characterization of a rhodium-alkenyl-thioether intermediate. These interesting results suggest that further mechanistic studies are desiderable to shed light on the mode of operation of the $\mathrm{Rh}-\mathrm{Tp} *$ initiators.

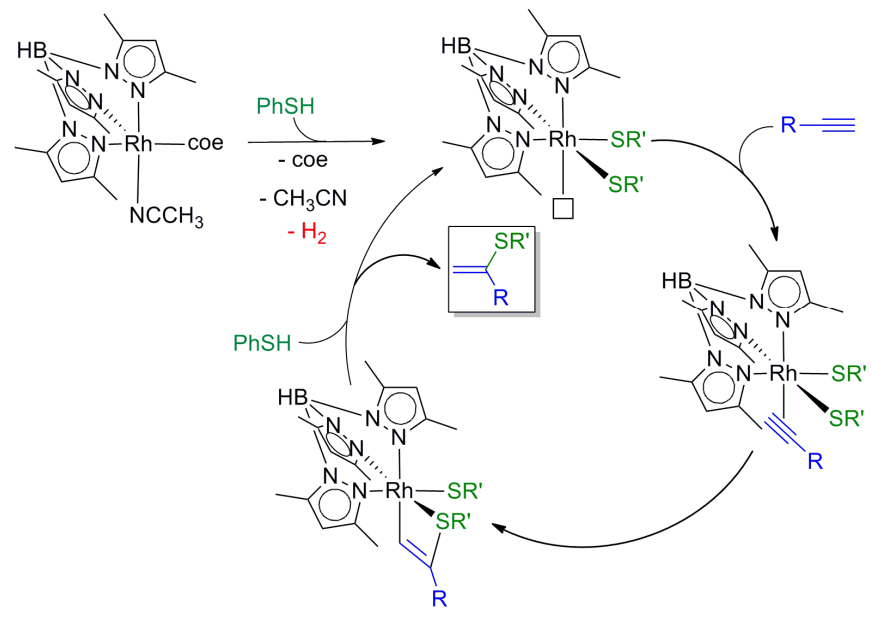

Scheme 18. Proposed mechanism for Mizobe's catalyst involving rhodium dithiolate intermediates.

A recent example of ligand-based regioselectivity control in rhodium-catalyzed hydrothiolation has been reported. ${ }^{[19 i]}$ Thus, we have found that dinuclear complexes of the type $\left[\operatorname{Rh}(\mu-\mathrm{Cl})(\operatorname{IPr})\left(\eta^{2}-\right.\right.$

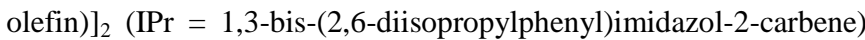
are very active hydrothiolation catalysts under mild conditions but are poorly selective for anti-Markovnikov thioethers (Scheme 19). Surprisingly, we subsequently found that the addition of 10 equivalents of pyridine to the catalytic system completely switches the regioselectivity outcome to $\alpha$-vinyl sulfides, although it also reduces the catalytic activity. Low-temperature NMR experiments and theoretical calculations showed that the role of pyridine is play on the coordination to metallic center. It has been demonstrated that the mechanism proceeds via oxidative addition of the $\mathrm{S}-\mathrm{H}$ bond to $\mathrm{Rh}^{\mathrm{I}}$ intermediates and successive alkyne insertion into the $\mathrm{Rh}-\mathrm{S}$ bond and reductive elimination steps, with insertion as the ratedetermining step. A likely explanation for the "pyridine effect" is as follows: the sterically hindered and strongly electron donating NHC ligand directs the coordination of the pyridine trans to it, consequently blocking coordination of the alkyne in this position. Simultaneously, the trans influence of the hydride paves the way to a cis thiolate-alkyne disposition, which subsequently gives rise to the branched vinyl sulfide regioisomer. 


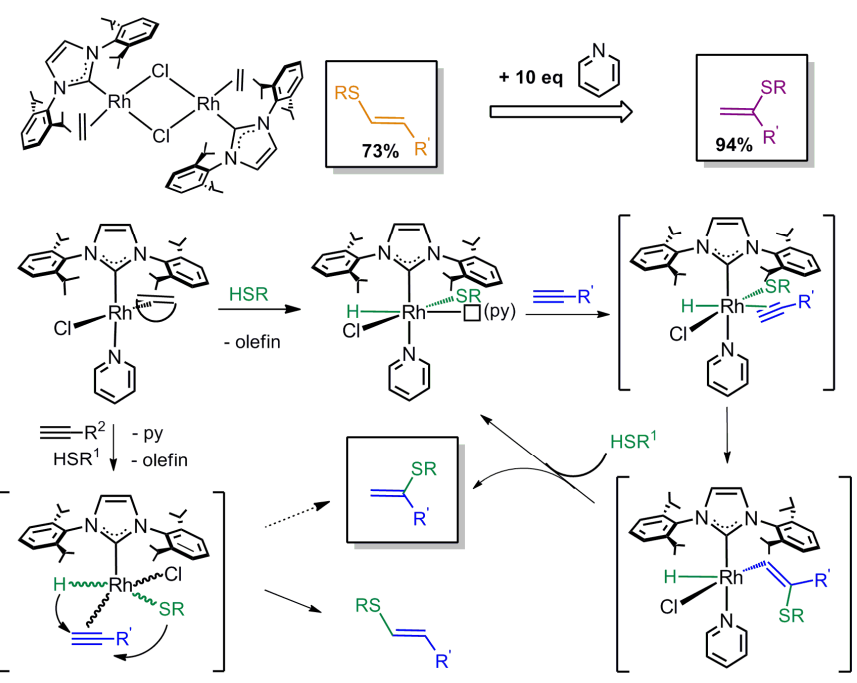

Scheme 19. Regioselectivity switch upon the addition of pyridine to Rh-NHC catalytic systems.

\section{Summary and Outlook}

In recent years, the hydrothiolation of unsaturated carboncarbon bonds, a practical and atom-economical reaction for the incorporation of sulfur into organic frameworks, is undergoing an impressive renaissance. Organometallic catalysts provide an excellent opportunity to develop synthetic methods for the selective addition of thiols to unsaturated carbon-carbon bonds, becoming a powerful tool for the control of the regio- and stereoselectivity, increasing at the same time catalytic activity under mild reaction conditions thereby drastically reducing the formation of unwanted by-products. In this minireview the mechanistic diversity of the hydrothiolation of unsaturated carbon-carbon bonds has been highlighted. The great array of metal catalyst operating through a variety of mechanisms and the ligand control on the selectivity certainly pave the way for a la carte preparation of a range of thiothers with application in organic synthesis, pharmaceuticals or functional materials. It is expected that the comprehensive mechanistic knowledge of this high atom-efficiency reaction will allow for the future design of more specific catalysts for the preparation of regular polymers, specific biomolecular structures, enantioselective synthesis and other valuable materials.

Received: ((will be filled in by the editorial staff))

Published online on ((will be filled in by the editorial staff))

[1] a) T. Kondo, T. Mitsudo, Chem. Rev. 2000, 100, 3205. b) E. Schaumann, Top. Curr. Chem. 2007, 274, 1. c) P. Bichler, J. Love, in Topics of Organometallic Chemistry, Vol 31 (Eds: A. Vigalok), SPRINGER-VERLAG, Heidelberg, 2010, pp. 39-64. d) I. P. Beletskaya, V. P. Ananikov, Chem. Rev. 2012, 111, 1596.

[2] a) C. A. Dvorak, W. D. Schmitz, D. J. Poon, D. C. Pryde, J. P. Lawson, R. A. Amos, A. I. Meyers, Angew. Chem. Int. Ed. 2000, 39, 1664. b) P. Johannesson, G. Lindeberg, A. Johansson, G. V. Nikiforovich, A. Gogoll, B. Synnergren, M. LeGrèves, F. Nyberg, A. Karlén, A. Hallberg, J. Med. Chem. 2002, 45, 1767. c) Á. Szilágyi, F. Fenyvesi, O. Mayercsik, I. S. Pelyvás, I. Bácskay, P. Fehér, J. Váradi, M. Vecsernyés, P. Herczegh, J. Med Chem. 2006, 49, 5626.

[3] a) A. Abe, Macromolecules 1980, 13, 546. b) E. Ahmed, F. S. Kim, H Xin, S. A. Jeneke, Macromolecules 2009, 42, 8615. c) E. Hoyle, C. N. Bowman, Angew. Chem. Int. Ed. 2010, 49, 1540.
[4] a) B. M. Trost, A. C. Lavoie, J. Am. Chem. Soc. 1983, 105, 5075. b) M. D. McReynolds, J. M. Dougherty, P. R. Hanson, Chem. Rev. 2004, 104, 2239. c) R. Fernández de la Pradilla, M. Tortosa, A. Viso, Top. Curr. Chem. 2007, 275, 103. d) Y. Cui, P. E. Floreancing, Org. Lett. 2012, 14,1720 .

[5] a) A. Ogawa, J. Organomet. Chem. 2000, 611, 463. b) I. P. Beletskaya, V. P. Ananikov, Eur. J. Org. Chem. 2007, 3431. c) I. P. Beletskaya, V. P. Ananikov, Pure Appl. Chem. 2007, 79, 1041. d) C. J. Weiss, T. J. Marks Dalton Trans. 2010, 39, 6576. e) A. Massi, D. Nanni, Org. Biomol. Chem. 2012, 10, 3791.

[6] a) T. Posner, Ber. Dtsch. Chem. Ges. 1905, 38, 646. b) E. P. Kohler, H. Potter, J. Am. Chem. Soc. 1930, 57, 1316. c) H. Bader, L. C. Cross, I. Heilbron, E. R. H. Jones, J. Chem. Soc. 1949, 619.

[7] a) K. Griesbaum, Angew. Chem. Int. Ed. 1970, 9, 273. b) Benati, L.; Capella, L.; Montevecchi, P. C.; Spagnolo P. J. Chem. Soc., Perkin Trans. 1 1995, 1035. c) M. Lo Conte, S. Pacifico, A. Chambery, A. Marra, A. Dondoni, J. Org. Chem. 2010, 75, 4644.

[8] a) V. N. Ipatieff, H. Pines, B. S. Friedman, J. Am. Chem. Soc. 1938, 60, 2731. b) F. Kipnis, J. Ornfelt, J. Am. Chem. Soc. 1951, 73, 822. c) F. Wolf, H. Finke Z. Chem. 1972, 12, 180 d) C. G. Screttas, M. Micha-Screttas, J. Org. Chem. 1979, 44, 713. e) S. Kanagasabapathy, A. Sudalai, B. C. Benicewicz, Tetrahedron Lett. 2001, 42, 3791.

[9] a) W. E. Truce, J. A. Simms, M. M. Boudakian, J. Am. Chem. Soc. 1956, 78, 695. b) D. H. Wadsworth, M. R. Detty, J. Org. Chem. 1980, 45, 4611. c) M. S. Waters, J. A. Cowen, J. C. McWilliams, P. E. Maligres, D. Askin, Tetrahedron Lett. 2000, 41, 141. d) A. Kondoh, K. Takami, H. Yorimitsu, K. Oshima, J. Org. Chem. 2005, 70, 6468. e) A. H. Yu, R. H. Qiu, N. Y. Tan, L. F. Peng, X. H. Xu, Chin. Chem Lett. 2011, 22, 687.

[10] J. K. Dunleavy, Platinum Metals Rev. 2006, 50, 110.

[11] J. V. McDonald, J. L. Corbin, W. E. Newton, Inorg. Chem. 1976, 15, 2056.

[12] a) T. Mukaiyama, T. Izawa, K. Saigo, H. Takei, Chem. Lett. 1973, 355. b) M. Belley, R. Zamboni, J. Org. Chem. 1989, 54, 1230.

[13] M. Weïwer, L. Coulombel, E. Duñach, Chem.Commun. 2006, 332.

[14] a) H. Kuniyasu, A. Ogawa, K.-I. Sato, I. Ryu, N. Kambe, N. Sonoda, J. Am. Chem. Soc 1992, 114, 5902. b) J.-E. Bäckvall, J. Org. Chem. 1994, 59, 5850. c) A. Ogawa, T. Ikeda, K. Kimura, J. Hirao, J. Am. Chem. Soc. 1999, 121, 5108. d) B. Gabriele, G. Salerno, A. Fazio, Org Lett. 2000, 2, 351. e) A. Kondoh, H. Yorimitsu, K. Oshima, Org. Lett. 2007, 9, 1383. f) V. P. Ananikov, N. V. Orlov, I. P. Beletskaya, V. N. Khrustalev, M. Y. Antipin, T. V. Timofeeva, J. Am. Chem. Soc. 2007, 129, 7252. g) S. Kodama, A. Nomoto, M. Kajitani, E. Nishinaka, M. Sonoda, A. Ogawa, J. Sulfur Chem. 2009, 30, 309. h) T. Mitamura, M. Daitou, A. Nomoto, A. Ogawa, Bull. Chem. Soc. Jpn. 2011, 84, 413. i) V. P. Ananikov, N. V. Orlov, S. S. Zalesskiy, I. P. Beletskaya, V. N. Khrustalev, K. Morokuma, D. G. Musaev J. Am. Chem. Soc. 2012 134, 6637. j) R. Gerber, C. M. Frech Chem. Eur. J. 2012, 18 , 8901.

[15] a) A. Ogawa, J.-I. Kawakami, M. Mihara, T. Ikeda, N. Sonoda, T. Irao, J. Am. Chem. Soc. 1997, 119, 12380.

[16] a) L.-B. Han, C. Zhang, H. Yazawa, S. Shimada, J. Am. Chem. Soc. 2004, 126, 5080 b) V. P. Ananikov, D. A. Malyshev, I. P. Beletskaya, G. G. Aleksandrov, I. L. Eremenko, Adv. Synth. Catal. 2005, 347, 1993. c) V. P. Ananikov, L. V. Orlov, I. P. Beletskaya, Organometallics, 2006, 25, 1970. d) D. A. Malyshev, N. M. Scott, N. Marion, E. D. Stevens, V. P. Ananikov, I. P. Beletskaya, S. P. Nolan, Organometallics, 2006, 25, 4462. e) V. P. Ananikov, S. S. Zalesskiy, N. V. Orlov, I. P. Beletskaya, Russ. Chem. Bull., Int. Ed. 2006, 55, 2109. f) V. P. Ananikov, K. A. Gayduck, N. V. Orlov, I. P. Beletskaya, V. N. Khrustalev, M. Y. Antipin, Chem. Eur. 2010, 16, 2063.

[17] U. Koelle, C. Rietmann, J. Tjoe, T. Wagner, U. Englert, Organometallics 2005, 14, 703. 
[18] J. R. Cabrero-Antonino, A. Leyva-Pérez, A. Corma, Adv. Synth. Catal. 2012, 354, 678 .

[19] a) C. Cao, L. R. Fraser, J. A. Love, J. Am. Chem. Soc. 2005, 127, 17614. b) Y. Misumi, H. Seino, Y. Mizobe, J. Organomet. Chem. 2006, 691, 3157. c) L. R. Fraser, J. Bird, Q. Wu, C. Cao, B. O. Patrick, J. A. Love, J. A. Organometallics 2007, 26, 5602. d) S. Shoai, P. Bichler, B. Kang, H. Buckley, J. A. Love, Organometallics 2007, 26, 5778. e) J. Yang, A. Sabarre, L. R. Fraser, B. O. Patrick, J. A. Love, J. Org. Chem. 2009, 74, 182. f) Y. Yang, R. M. Rioux, Chem. Commun. 2011, 47, 6557. g) J. Liu, J. W. Y. Lam, C. K. W. Jin, J. C. Y. Ng, J. Shi, H. Su, K. F. Yeung, Y. Hong, M. Faisal, Y. Yu, K. S. Wong, B. Z Tang, Macromolecules 2011, 44, 68. h) H. Zhao, J. Peng, M. Cai, Catal. Lett. 2012, 142, 138. i) A. Di Giuseppe, R. Castarlenas, J. J. Pérez-Torrente, M. Crucianelli, V. Polo, R. Sancho, F. J. Lahoz, L. A. Oro, J. Am. Chem. Soc. 2012, 134, 8171.

[20] a) S. Burling, L. D. Field, B. A. Messerle, K. Q. Vuong, P. Turner, Dalton Trans. 2003, 4181. b)L. D. Field, B. A. Messerle, K. Q. Vuong, P. Turner, Dalton Trans. 2009, 3599.

[21] a) S. A. Delp, C. Munro-Leighton, L. A. Goj, M. A. Ramírez, T. B. Gunnoe, J. L. Petersen, P. D. Boyle, Inorg. Chem. 2007, 46, 2365. b) C. Munro-Leighton, S. A. Delp, N. M. Alsop, E. D. Blue, T. B. Gunnoe, Chem. Commun. 2008, 111. c) Z. L. Wang, R. Y. Tang, P. S. Luo, C. L. Deng, P. Zhong, J. H. Li, Tetrahedron 2008, 64, 10670. d) S. Ranjit, Z. Duan, P. Zhang, X. Liu, Org. Lett. 2010, 12, 4134. e) S. N. Riduan, J. Y. Ying, Y. Zhang, Org. Lett. 2012, 14, 1780. f) I. G. Trostyanskaya, I. P. Beletskaya, Synlett 2012, 23, 535.

[22] a) N. Morita, N. Krause, Angew. Chem. Int. Ed. 2006, 45, 1897. b) C. Brouwer, R. Rahaman, C. He, Synlett 2007, 11, 1785 b) L. L. Santos, V. R. Ruiz, M. J. Sabater, A. Corma, Tetrahedron 2008, 64, 7902. c) A. Corma, C. González-Arellano, M. Iglesias, F. Sánchez, Appl. Catal., A 2010, 375, 49. d) Menggenbateer, M. Narsireddy, G. Ferrara, N. Nishima, T. Jin, Y. Yamamoto, Tetrahedron Lett. 2010, 51, 4627.

[23] a) Y. Higuchi, S. Atobe, M. Tanaka, I. Kamiya, T. Yamamoto, A. Nomoto, M. Sonoda, A. Ogawa, Organometallics 2011, 30, 4539. b) V. Girijavallabhan, C. Alvarez, F. G. Njoroge, J. Org. Chem. 2011, 76, 6442

[24] a) M. Weiwer, E. Duñach, Tetrahedron Lett. 2006, 47, 2464. b) J. S. Yadav, B. V. S. Reddy, A. Raju, K. Ravindar, G. Baishya, Chem. Lett. 2007, 36, 1474. c) M. Weïwer, X. Chaminade, J. C. Bayón, E. Duñach, Eur. J. Org. Chem. 2007, 2464. d) R. Sarma, N. Rajesh, D. Prajapati, Chem. Commun. 2012, 48, 4014 e) N. Legrave, A. Couhert, S. Olivero, J. R. Desmurs, E. Duñach Eur. J. Org. Chem. 2012, 901.

[25] a) V.-H. Nguyen, H. Nishino, S. Kajikawa, K. Kurosawa, Tetrahedron 1998, 54, 11445. b) J. Zhou, G.-L. Zhang, J.-P. Zou, W. Zhang, Eur. J. Org. Chem. 2011, 3412.

[26] F. E McDonald, S. A. Burova, L. G. Huffman Jr, Synthesis 2000, 970.

[27] C. J. Weiss, T. J. Marks, J. Am. Chem. Soc. 2010, 132, 1053.

[28] a) C. J. Weiss, S. D. Wobser, T. J. Marks, J. Am. Chem. Soc. 2009 131, 2062. b) C. J. Weiss, S. D. Wobser, T. J. Marks, Organometallics 2010, 29, 6308 .

[29] a) M. Marigo, T. Schulte, J. Franzén, K. A. Jørgensen, J. Am. Chem. Soc. 2005, 127, 15710. b) W. Wang, H. Li, J. Wang, L. Zu, J. Am. Chem. Soc. 2006, 128, 10654. c) P. Melchiorre, M. Marigo, A. Carlone, G. Bartoli, Angew. Chem. Int. Ed. 2008, 47, 6138. d) X.-F. Wang, Q.-L- Hua, Y. Cheng, X.-L. An, Q.-Q. Yang, J.-R. Chen, W.-J. Xiao, Angew. Chem. Int. Ed. 2010, 49, 8279. e) V. Blanco, A. Carlone, K. D. Hänni, D. A. Leigh, B. Lewandowski, Angew. Chem. Int. Ed. 2012, 51,5166 .
[30] H. C. Kolb, M. G. Finn, K. B. Sharpless, Angew. Chem. Int. Ed. 2001, 40, 2004

[31] a) R. K. Dieter, L. A. III Silks, J. R. Fishpaugh, M. E. Kastner, J. Am. Chem. Soc. 1985, 107, 4679. b) S. Yaghoub, M. Sadatshahabi, K. Alimohammadi, M. Tajbakhsh, Green Chem. 2011, 13, 2851.

[32] P. Kumar, R. Kumar Pandey, V. R. Hegde, Synlett 1999, 1921.

[33] S. Banerjee, J. Das, S. Santra, Tetrahedron Lett. 2009, 50, 124.

[34] S. Thurow, N. T. Ostosi, S. R. Mendes, R. G. Jacob, E. J. Lenardão, Tetrahedron Lett. 2012, 53, 2651.

[35] M. S. Silva, R. G. Lara, J. M. Marczewski, R. G. Jacob, E. J. Lenardão, Tetrahedron Lett. 2008, 49, 1927.

[36] a) R. Sridhar, K. Surendra, N. S. Krishnaveni, B. Srinivas, K. R. Rao, Synlett 2006, 3495. b) B. C. Ranu, T. Mandal, Synlett 2007, 925. c) S. Bhadra, B. C. Ranu, Can. J. Chem. 2009, 87, 1605. d) Z. Jin, B. Xu, G. B. Hammond, Eur. J. Org. Chem. 2010, 168.

[37] A. Corma, A. Leyva-Pérez, M. J. Sabater, Chem. Rev. 2011, 111, 1657.

[38] C. Bruneau, P. H. Dixneuf, Angew. Chem. Int. Ed. 2006, 45, 2176.

[39] a) P. Schollhammer, N. Cabon, J.-F. Capon, F. Y. Pétillon, J. Talarmin, K. W. Muir, Organometallics 2001, 20, 1230. b) T. Ikada, Y. Mizobe, M. Hidai, Organometallics 2001, 20, 4441. c) H. Kuniyasu, F. Yamashita, J. Terao, N. Kambe, Angew. Chem Int. Ed. 2007, 46, 5929 .

[40] Examples where reductive elimination is proposed as the key step: a) R. Ghosh, X. Zhang, P. Achord, T. J. Emge, K. Krogh-Jespersen, S. A. Goldman, J. Am. Chem Soc. 2007, 129, 853. b) I. F. D. Hyatt, H. K. Anderson, A. T. Jr. Morehead, A. L. Sargent, Organometallics 2008, 27, 135. c) C. González-Rodríguez, R. J. Pawley, A. B. Chaplin, A. L. Thompson, A. S. Weller, M. C. Willis, Angew. Chem. Int. Ed. 2011, 50,5134

[41] Some examples of 2,1 alkyne addition into a M-H bond: a) W. Weng, S. Parking, O. V. Ozerov, Organometallics 2006, 25, 5345. b) L. She, X. Li, H. Sun, J. Ding, M. Frey, H.-F. Klein, Organometallics 2007, $26,566$.

[42] A. Ohtaka, H. Kuniyasu, M. Kinomto, H. Kurosawa, J. Am. Chem. Soc. 2002, 124, 14324

[43] H. Kuniyasu, K. Takekawa, F. Yamashita, K. Miyafuji, S. Asano, Y. Takai, A. Ohtaka, A. Tanaka, K. Sugoh, H. Kurosawa, N. Kambe, Organometallics 2008, 27, 4788.

[44] T. J. Marks, C. J. Weiss, S. D. Wobser, (U.S. Patent), US 2011/0040098, 2011.

[45] K.Q. Vuong Ph.D. Thesis. University of New South Wales, Australia, 2006

[46] a) I. Ojima, N. Clos, R. J. Donovan, P. Ingallina, Organometallics 1990, 9, 3127. b) B. M. Trost, Z. T. Ball, J. Am. Chem. Soc. 2005, 127, 17644.

[47] Some representative examples of ligand-controlled regioselectivity in other X-H additions with Pd catalysts: a) L.-B. Han, R. Hua, M. Tanaka, Angew. Chem. Int. Ed. 1998, 37, 94. b) I. Kamiya, E. Nishinaka, A. Ogawa, J. Org. Chem. 2005, 70, 696. c) V. Ananikov, J. V. Ivanova, L. L. Khemchyan, I. P. Beletskaya, Eur. J. Org. Chem. 2012, 3830 .

[48] H. Singer, G. Wilkinson, J. Chem. Soc. A 1968, 2516.

[49] S. Shoai Ph.D. Thesis. University of British Columbia, Canada, 2010. 
